\title{
A LICITAÇ̃̃O E OS PRINCÍPIOS DA ECONOMICIDADE E DA ISONOMIA FRENTE AO DESENVOLVIMENTO NACIONAL SUSTENTÁVEL
}

Laerte Radtke Karnopp*

\section{RESUMO}

$\mathrm{O}$ artigo tem como objeto a possibilidade de harmonização dos princípios da economicidade e da isonomia com a promoção do desenvolvimento nacional sustentável nas licitações públicas e tem como problema averiguar a viabilidade de sua coexistência no ordenamento jurídico. $\mathrm{O}$ objetivo é o de refletir sobre a adequação do procedimento licitatório à realidade jurídica imposta pela norma que determina à administração pública que promova o desenvolvimento sustentável por meio de suas aquisições. O método empregado foi o dedutivo, para concluir pela resposta afirmativa ao problema de pesquisa.

Palavras-chave: Licitação; Compras públicas; Desenvolvimento sustentável; Economicidade; Isonomia.

\section{THE BIDDING PROCESS AND THE PRINCIPLES OF ECONOMICS AND ISONOMY TOWARDS SUSTAINABLE NATIONAL DEVELOPMENT}

\begin{abstract}
The article aims at harmonizing the principles of economics and isonomy with the promotion of sustainable development in public bids and has the problem of ascertaining the feasibility of their coexistence in the legal system. The objective is to reflect about the adequacy of the bidding procedure to the legal reality imposed by the standard that determines to the public administration that promotes the sustainable development through its acquisitions. The method used was the deductive, to conclude by the affirmative answer to the research question.
\end{abstract}

Keywords: Bidding; Public procurement; Sustainable development; Economicity; Isonomy.

\section{INTRODUÇÃO}

O trabalho aborda a possibilidade de coexistência e harmonização dos princípios da economicidade e da isonomia com a promoção do desenvolvimento nacional sustentável nas licitações públicas. Para tanto, analisará os princípios específicos das licitações públicas, com ênfase nos princípios da economicidade e da isonomia, em cotejo com a nova garantia de promoção do desenvolvimento nacional sustentável nas licitações, inserida no art. $3^{\circ}$ da Lei n. 8.666/93 (BRASIL, 1993) pela Lei n. 12.349/2010.

\footnotetext{
* Mestrando em Direito, Bacharel em Direito e Licenciado em Letras pela Universidade Federal de Pelotas (UFPel), Auditor Geral do Instituto Federal de Educação, Ciência e Tecnologia Sul-rio-grandense (IFSul), laerterk@gmail.com.
} 
O problema a ser abordado situa-se na inserção desse novo princípio no caput do artigo $3^{\circ}$ da Lei de Licitações (BRASIL, 1993), no mesmo patamar do princípio constitucional da isonomia e da seleção da proposta mais vantajosa para a administração pública, questionandose a possibilidade de harmonização entre eles.

Essa reflexão tem o objetivo de esclarecer a dúvida sobre a possibilidade de harmonizar esse novo princípio com os já existentes, por sugerir, inicialmente, uma aparente contrariedade, fazendo supor que não poderiam coexistir. Desta forma, este trabalho se propõe a analisar se a promoção do desenvolvimento nacional sustentável através do procedimento licitatório é compatível com a isonomia e a seleção da melhor proposta, o que constitui seu objetivo central.

Para desenvolver o tema, o artigo será dividido em três seções. A primeira terá como objetivo a apresentação da evolução do conceito de desenvolvimento para desenvolvimento sustentável no âmbito da legislação constitucional e infraconstitucional, trazendo a lume o panorama internacional da preservação do meio ambiente. A segunda, por sua vez, irá situar as licitações no contexto do desenvolvimento sustentável, considerando o panorama legislativo. A terceira, ao final, irá enfrentar o problema da promoção do desenvolvimento sustentável por meio das compras públicas, diante dos princípios da economicidade e da isonomia.

A pesquisa orientar-se-á pelo método dedutivo, considerando-se, como premissa maior, que o desenvolvimento sustentável é princípio que orienta todos os atos da administração pública; como premissa menor, que a licitação é ato da administração pública; e, como conclusão, que o procedimento licitatório deve ser regido pelo princípio do desenvolvimento sustentável.

\section{O DESENVOLVIMENTO SUSTENTÁVEL E O PODER PÚBLICO: DO DESENVOLVIMENTO AO DESENVOLVIMENTO SUSTENTÁVEL}

A literatura apresenta dois sentidos para o termo "desenvolvimento": um que é relacionado à evolução do sistema de produção, acumulação e progresso técnico e outro pertinente ao grau de satisfação das necessidades humanas. Ambos os sentidos exigem a compreensão dos seus desdobramentos, sendo um deles o interesse dos grupos econômicos dominantes na utilização dos recursos naturais (FURTADO, 1980).

O crescimento do consumo tem trazido um significativo aumento da produção industrial que, por sua vez, acaba por conduzir à aniquilação dos recursos naturais não 
renováveis. Esse movimento levou ao esgotamento dos recursos naturais nos países desenvolvidos, fazendo com que, para manter esse modelo de produção, estes passassem a buscar recursos naturais nos países periféricos, que possuem, ainda, maior quantidade desse tipo de recursos (NEVES et al, s. d.).

Esses mesmos autores defendem que "o ataque ao meio ambiente está diretamente relacionado à lógica do modelo atual de produção, com seu aparato tecnológico, desenvolvido pelos países do núcleo orgânico do capitalismo e difundido como forma de progresso ideal" (NEVES et al, s. d., p. 2). Em consequência, diante do significativo aumento populacional do planeta, faltarão recursos naturais para atender as necessidades humanas para a conservação de um padrão médio de vida.

Veiga (2008) apresenta três correntes que revelam diferentes entendimentos sobre desenvolvimento. A primeira é a dos fundamentalistas, segundo a qual o significado de desenvolvimento equivale a crescimento econômico. Essa relação de sinonímia entre desenvolvimento e crescimento econômico, segundo o autor, caiu por terra quando o Programa de Nações Unidas para o Desenvolvimento (PNUD) lançou o Relatório do Desenvolvimento Humano, consagrando um entendimento de que o crescimento econômico de uma nação não significa necessariamente o acesso da população aos bens materiais produzidos.

A segunda corrente é a denominada pós-modernista, que considera o desenvolvimento como um mito, abrangendo neste, inclusive, o próprio desenvolvimento sustentável (NEVES et al, s. d.). Essa corrente é capitaneada pelo italiano Giovanni Arrighi, que, no ensinamento de Veiga (2008), sustenta que há uma sólida e intransponível divisão entre os países na ordem mundial, de modo que não é possível a todos os Estados a participação no núcleo orgânico. Para a sobrevivência do desenvolvimento, é necessário que exista o subdesenvolvimento, visto como um estado transitório, para que nações dos grupos semiperiférico e periférico persigam o desejo de integrarem o núcleo composto pelos países em avançado estado de desenvolvimento.

A última corrente se fortalece com o Relatório do Desenvolvimento Humano em 1990 e pressupõe que desenvolvimento se relaciona com a liberdade, a qual abrangeria questões culturais, sociais e outras. Tal noção é a que mais se aproxima, na atualidade, com o conceito de desenvolvimento sustentável (NEVES et al, s. d.).

Referido modelo de desenvolvimento passou a ser questionado a partir dos anos 60 e 70 (NEVES et al, s. d.), quando surgiram os primeiros contornos do que hoje é denominado desenvolvimento sustentável, mais precisamente em 1972, na Conferência das Nações Unidas 
sobre o Meio Ambiente Humano (United Nations Conference on the Human EnvironmentUNCHE). A Declaração de Estocolmo, segundo Porto et al (2011), delineou os princípios da preservação e da melhoria do ambiente natural, além de reforçar a necessidade de apoio financeiro e assistência técnica a grupos de pessoas e nações economicamente mais desfavorecidas.

O grande marco do desenvolvimento sustentável, no entanto, foi o ano de 1987, quando a presidente da Comissão Mundial sobre o Meio Ambiente e Desenvolvimento, Gro Harlem Brundtland, apresentou para a Assembleia Geral da Organização das Nações Unidas (ONU) o documento "Nosso Futuro Comum" (Our Common Future), também conhecido como Relatório Brundtland.

Gro Brundtland, primeira-ministra norueguesa, foi convidada pelo Secretário-Geral da ONU para presidir essa Comissão em 1983, em face da preocupação existente em relação à "forte pressão do crescimento populacional, a moderna tecnologia, bem como a demanda do consumidor sobre o tecido planetário, especialmente desde 1970" (PORTO et al, 2011, p. 4344). O mote do documento é a manutenção do avanço social e econômico capaz de garantir aos seres humanos uma vida saudável e produtiva, sem que, no entanto, não restasse comprometida a capacidade de as gerações futuras poderem suprir suas próprias necessidades.

O desenvolvimento global sustentável, nessa esteira, exige a mudança de atitude daqueles que têm mais acesso à tecnologia no sentido de adotarem estilos de vida dentro dos meios ecologicamente sustentáveis do planeta - em seu uso de energia, por exemplo (PORTO et al, 2011).

Para que o desenvolvimento ocorresse de maneira sustentável, passou-se a entender que as políticas públicas adotadas pelos entes nacionais deveriam ser dotadas de eficiência econômica, política, social e cultural, de modo a utilizar os recursos naturais de forma consciente, para evitar o seu esgotamento, pois tal fenômeno poderia tornar-se irreversível. Nesta linha, segundo Araújo, “a sustentabilidade aparece como um processo contínuo a ser constantemente impulsionado, o que se dá na busca de uma coexistência dos ecossistemas e dos modos de vida relativamente aos quais eles constituem o suporte” (2011, p. 272).

Dessa forma, apesar da ampla repercussão alcançada pelo Relatório Brudtland, em razão da sensação de fracasso que predominava em relação ao tema no final da década de 1980, a ONU convocou a Conferência sobre Meio Ambiente e Desenvolvimento, que aconteceu em 1992 na cidade do Rio de Janeiro, passando a ser conhecida como Eco-92 ou Rio-92. 
Sobre a realização desse evento, que reuniu grandes lideranças mundiais engajadas na questão do meio ambiente, pode-se afirmar que

\begin{abstract}
A iniciativa foi um divisor de águas, onde o tema do desenvolvimento sustentável ganhou força política e relevância, apesar do conflito de interesses econômicos entre países ricos e pobres. Durante o encontro de 1992, foram assinadas as convenções sobre diversidade biológica e mudança do clima, e também a Carta da Terra declaração de princípios éticos fundamentais para a construção de uma sociedade global justa, sustentável e pacífica. Além disso, os países aprovaram um relatório de mais de 800 páginas detalhando o necessário para se promover essa reviravolta, a ser adotado em cada país: a Agenda 21 (BETIOL et al, 2012, p. 20).
\end{abstract}

A Rio-92 foi marcada pelas discussões sobre a insustentabilidade do modelo de desenvolvimento vigente à época. Nesse sentido, destaca-se o Princípio 8 da Declaração sobre Meio Ambiente e Desenvolvimento, firmada no evento, o qual possui o seguinte teor: "Para atingir o desenvolvimento sustentável e mais alta qualidade de vida para todos, os Estados devem reduzir e eliminar padrões insustentáveis de produção e promover políticas demográficas adequadas" (citado por TORRES, 2012, p. 1).

Na mesma ocasião, foi construída a Agenda 21, importante documento sinalizador dos princípios e diretrizes do desenvolvimento sustentável para todas as nações signatárias. Esse documento enfatiza, entre outras questões, o problema do consumo, que assume o centro das discussões sobre sustentabilidade. A Agenda 21 indica como causas da deterioração ambiental o consumo e a produção de acordo com padrões insustentáveis, alertando para a demanda de recursos naturais decorrentes desse modelo de consumo e a necessidade da busca pela redução do esgotamento desses recursos. Do mesmo modo, sinaliza para o papel dos governos no consumo, especialmente nos países onde ocupa posição relevante na economia, recomendando a estes a observância de critérios ecológicos na sua política de compras. O papel da Agenda 21 foi decisivo na mudança de orientação das compras governamentais, uma vez que o poder público é responsável por significativo percentual das aquisições e serviços existentes no mercado.

Nesse sentido, Betiol destaca que:

É expressivo o peso do consumo público nas economias nacionais, com estimativa de variar entre $8 \%$ e $25 \%$ do Produto Interno Bruto (PIB). A partir desse poder de influenciar o mercado, os países têm se movimentado para formular novas políticas públicas de compras, provocando impactos no setor produtivo, como um "efeito dominó". Para estimular práticas positivas que no final das contas revertam para o bem-estar da sociedade, governos das várias esferas usam a força do exemplo e fazem a lição de casa adotando critérios sociais e ambientais nas licitações de serviços em geral, obras e compra de materiais - desde papel de escritório e copos para água e cafezinho até computadores e veículos (BETIOL et al, p. 22-23). 
$\mathrm{Na}$ capacidade de influenciar o mercado é que reside um dos mais relevantes instrumentos do poder público para transformar as relações de consumo. Devido ao fato de o volume de compras da administração pública ser de tal monta, é plenamente viável que esta possa induzir o mercado para uma produção mais ecológica e, por consequência, a um consumo menos agressivo para o meio ambiente.

Realizou-se, em 2002, na cidade de Johanesburgo, a Cúpula Mundial de Desenvolvimento Sustentável, conhecida como Rio+10, quando foi lançado o Plano de Implementação de Johanesburgo. Uma das diretrizes inseridas nesse documento foi a promoção de políticas de compras públicas incentivadoras do desenvolvimento e da disseminação de bens e serviços ambientalmente saudáveis (TORRES, 2012, p. 2).

Assim, reconheceu-se, em definitivo, a importância do poder público como impulsionador da sustentabilidade na cadeia produtiva, pois,

\begin{abstract}
Ao se engajar em uma proposta de desenvolvimento sustentável, o poder público deve interceder para transformar padrões produtivos e as formas de se comprar e consumir. Para isso, pode promover estilos de vida e comportamentos mais sustentáveis, remodelar sua própria infraestrutura, elaborar normas e criar incentivos econômicos favoráveis à conservação dos recursos naturais e à felicidade humana. Isso significa, entre outras ações, abolir ou revisar políticas que dificultam o consumo e a produção sustentável, criar políticas que promovam e proporcionem padrões de vida fundados em bem-estar, e melhorar o desempenho e os procedimentos das contratações públicas. Visando induzir a transformação e adaptação do mercado, o poder público pode instituir subsídios e incentivos fiscais a atividades mais sustentáveis - como a produção agroecológica, por exemplo - e, por outro lado, eliminar os incentivos e aumentar a tributação de atividades que geram impactos negativos aos ecossistemas e à sociedade, como as indústrias altamente dependentes de petróleo. Ainda que todas essas ações sejam realizadas, é essencial que a administração pública faça suas compras e contratações de forma sustentável, sendo exemplo para a sociedade e para as empresas, fomentando um mercado mais equitativo e ético (BETIOL et al, 2012, p. 24).
\end{abstract}

Referida opinião converge para o papel fomentador de que o poder público é dotado na definição de políticas e de comportamentos sustentáveis. Tudo isto incentiva o mercado a utilizar meios mais ecológicos e menos agressivos aos recursos naturais na produção de bens e serviços, uma vez que o poder público, como grande comprador, passará a instituir essa exigência nas suas aquisições.

Para Araújo (2011), o governo deve ser incumbido de promover políticas públicas em todos os níveis, para que estas sirvam como base a todas as ações. Para isto, é necessário ao poder público institucionalizar instrumentos econômicos hábeis a promover a sustentabilidade.

O poder público brasileiro, nesse compasso, passou a atuar na promoção do desenvolvimento sustentável, apresentando o arcabouço normativo que presta suporte a esse 
objetivo. Dessa forma, o legislador alterou a Lei de Licitações (BRASIL, 1993), de modo a esclarecer a relevância dessa ação governamental no incentivo do desenvolvimento sustentável no cenário nacional.

\section{A LICITAÇÃO E A PROMOÇÃO DO DESENVOLVIMENTO NACIONAL SUSTENTÁVEL}

A Agenda 21, aprovada em 1992 na Conferência das Nações Unidas sobre Meio Ambiente e Desenvolvimento (Rio-92), reservou um capítulo para tratar sobre as mudanças nos padrões de consumo, o qual foi desdobrado em duas áreas temáticas, das quais uma foi destinada a discutir o desenvolvimento de políticas e estratégias nacionais de estímulo e mudanças nos padrões insustentáveis de consumo (CONFERÊNCIA..., 1992).

Essa área temática parte da necessidade de eficiência na produção e mudanças nos padrões de consumo, de modo a otimizar o uso dos recursos e diminuir o desperdício ao mínimo. Para isso, segundo o documento, o poder público deve atuar para a promoção da eficiência nos processos produtivos e a redução do consumo perdulário no processo de crescimento econômico, levando em consideração as necessidades dos países em desenvolvimento; o desenvolvimento de uma estrutura política interna que estimule a mudança para padrões de produção e consumo mais sustentáveis; e o fortalecimento de valores que estimulem a produção e o consumo sustentáveis e as políticas que incentivem a transferência de tecnologias ambientalmente saudáveis para países em desenvolvimento (CONFERÊNCIA..., 1992).

A Agenda 21, nesse contexto, propôs como ação o exercício da liderança por meio das aquisições pelos governos, considerando estes como agentes capazes de exercer influência sobre as decisões empresariais e as opiniões do público, especialmente onde o setor público detém uma posição de maior relevância na economia. Daí a importância de a administração pública rever as políticas de aquisições e contratações de seus órgãos.

Moreira (2011) informa que na Conferência das Nações Unidas sobre Desenvolvimento Sustentável, realizada em Joanesburgo, na conhecida Conferência Rio+10, no ano de 2002, o assunto voltou à pauta com a construção do Plano de Implementação da Conferência, no qual foi proposto às autoridades nacionais que fossem consideradas soluções 
que respeitassem aos princípios da sustentabilidade na promoção do desenvolvimento nacional e local. O Capítulo III do referido documento apresenta a seguinte redação:

19. Incentivar as autoridades competentes de todos os níveis para que levem em consideração as questões do desenvolvimento sustentável na tomada de decisões, inclusive no planejamento do desenvolvimento nacional e local, nos investimentos em infraestrutura, no desenvolvimento empresarial e nas compras públicas. Para tanto, requer-se que sejam tomadas medidas em todos os níveis para: a) prestar apoio ao desenvolvimento de estratégias e programas de desenvolvimento sustentável, incluindo a tomada de decisões sobre os investimentos em infraestrutura e desenvolvimento comercial; b) continuar promovendo a internalização dos custos ambientais e o uso de instrumentos econômicos, levando em conta o princípio de que o agente poluidor deve, em princípio, arcar com os custos da poluição, de acordo com os interesses públicos, e sem distorcer as práticas comerciais e os investimentos internacionais; c) promover as políticas de compras públicas que incentivem o desenvolvimento e a disseminação de bens e serviços ambientalmente saudáveis; d) propiciar a capacitação e o treinamento para ajudar as autoridades competentes em relação à implementação das iniciativas indicadas neste parágrafo; e) utilizar procedimentos de avaliação do impacto ambiental (citado por MOREIRA, 2011, p. 302).

Verifica-se que todas as medidas recomendadas às autoridades nacionais foram, em certa medida, implementadas, pela via legislativa no Estado brasileiro. Especial atenção deve ser dedicada ao item "c", que recomenda a adoção de políticas de compras voltadas ao desenvolvimento e à disseminação de bens e serviços que valorizem a sustentabilidade.

Ainda no ano de 2002, o Conselho da Organização para a Cooperação e Desenvolvimento Econômico (OCDE) construiu um documento recomendando o aprimoramento do desempenho ambiental das contratações públicas, no qual reforça a necessidade de os governos tomarem posição de liderança nos processos destinados à realização do desenvolvimento sustentável e a contribuição que as políticas de licitações sustentáveis podem proporcionar na difusão de bens e serviços menos prejudiciais ao meio ambiente.

O documento traz uma ampla abordagem das contratações públicas sustentáveis, a começar pela criação legislativa, incentivando os países à regulamentação desse tipo de contratação. Em última análise, além de definir seus contornos, a inserção de uma regulamentação sólida no ordenamento jurídico proporciona maior segurança ao gestor para determinar formas inovadoras de contratação, visto que a variável ambiental ainda é recente nas compras públicas.

A recomendação apresentada pela OCDE passa, ainda, pela oferta de condições financeiras, orçamentárias e contábeis, tendo em vista que, na maioria das vezes, os custos desse tipo de bens e serviços tende a ser superior aos comuns. É necessário, portanto, que sejam 
viabilizados, a todos os órgãos públicos, recursos orçamentários e financeiros suficientes para permitir custear esse tipo de licitação.

A capacitação dos agentes públicos para a organização de licitações sustentáveis é outro ponto recomendado pelo documento. Ao tecer tal recomendação, a OCDE está a reconhecer a importância da devida formação dos técnicos que irão, ao fỉm, ser encarregados do planejamento e da execução dos certames licitatórios, bem como os usuários dos bens e serviços, certamente com vistas ao aperfeiçoamento constante desse tipo de contratação. A recomendação também trata da identificação de produtos e serviços de acordo com os objetivos das políticas de contratação sustentável, para a qual é necessária a informação e a formação dos agentes públicos, que deverão ser capacitados para a escolha mais qualificada desses bens e serviços.

A disseminação das informações necessárias à implementação das políticas também é ponto de relevância da recomendação, como meio de incentivar a opção governamental pelas compras sustentáveis e pela identificação de seus benefícios.

Por fim, o documento não se olvida da importância de mensurar o progresso das aquisições com foco na sustentabilidade e, também, as políticas como um todo, avaliando se são eficientes do ponto de vista econômico e efetivas sob o viés ambiental. Isto deverá acontecer, segundo o documento, mediante a criação de indicadores e de avaliação das políticas de compras.

Segundo dados apresentados por Moreira (2011), o poder público brasileiro investe, por ano, o correspondente a, aproximadamente, 15\% do Produto Interno Bruto (PIB) nacional em suas compras, o que corresponde a 600 bilhões de reais. Neste contexto, dado o grande poder de compra da administração pública, seu comportamento certamente tem o condão de influenciar o mercado para a produção de bens e serviços com base em critérios de sustentabilidade e de respeito ao meio ambiente. Sobre esse contexto, Torres (2012) afirma que

\footnotetext{
Ante o elevado montante de recursos gastos por União, Estados, Distrito Federal e Municípios, a adoção de licitações sustentáveis já representaria um ganho substancial em termos de redução de impacto ambiental. Mas as reais consequências que isso geraria seriam ainda maiores do que aquelas oriundas diretamente dessas compras governamentais. Haveria ainda outros impactos como o de sinalização para o setor privado de um novo paradigma de consumo, que se somaria às iniciativas já existentes em empresas privadas, no sentido de serem mais sustentáveis.
}

Em outras palavras, além de exigir o fornecimento de bens e a prestação de serviços sustentáveis, a administração pública estaria a estimular o mercado a aprimorar cada vez mais 
os aspectos voltados à conservação do meio ambiente. Com o passar do tempo, a demanda por bens e serviços sustentáveis cresceria, fazendo com que fosse reduzido o custo de produção, o que incentivaria o setor privado a investir mais no lançamento de produtos sustentáveis no mercado.

Nas palavras de Torres (2012), surgiria um círculo virtuoso, no qual a administração pública teria o papel de induzir o mercado a produzir bens e serviços mais sustentáveis, que, por sua vez, fariam a retroalimentação da administração com esses bens e serviços. Na verdade, não só o poder público seria beneficiado, mas também toda a coletividade, que teria à disposição bens e serviços mais corretos do ponto de vista ambiental. Vieira et al (2013) assente com essa informação, destacando que "o Estado brasileiro é um grande consumidor e detentor do poder de compra de bens, obras e serviços", razão pela qual é hábil a disseminar a cultura de proteção do meio ambiente.

Apesar da possibilidade de as licitações sustentáveis terem, potencialmente, todo esse alcance e embora seja possível encontrar, nos dias atuais, um largo arcabouço normativo no ordenamento jurídico brasileiro que versa sobre o tema, ainda não há norma geral nacional para dar tratamento organizado ao assunto. Por essa razão, é necessário examinar o complexo normativo sobre o tema desde as suas raízes para compreender o estado em que se encontra atualmente.

Machado (2008) consigna que a Constituição Federal (BRASIL, 1988), no artigo 225, não dá ao poder público a propriedade dos bens ambientais, mas lhe confere a qualidade de gestor ou gerente desses bens, e, em razão do fato de estes não serem dele, deve prestar contas ao povo sobre a administração dos bens de uso comum. Além da previsão genérica de gestão dos bens ambientais, a Constituição Federal (BRASIL, 1988), no artigo 170, VI, incumbe ao poder público a defesa do meio ambiente.

Assim, apesar da ausência de norma geral para detalhar a inserção da variável ambiental nas contratações públicas, o ordenamento jurídico é suficiente para o desenvolvimento de ações voltadas ao desenvolvimento econômico e social orientado pela defesa do meio ambiente, de modo que seja permitida à administração pública a escolha de bens e serviços de menor impacto negativo sobre a natureza.

Moreira afirma que, “em sentido contrário e complementar, devem ser preteridos produtos e serviços que, embora atraentes quando considerados critérios puramente econômicos, sejam ofensivos ou desinteressantes sob o prisma socioambiental" (2011, p. 319320). 
Para atender essa perspectiva e em consonância com a norma constitucional, o poder legislativo promoveu a alteração da Lei de Licitações (BRASIL, 1993) para dar conta do incentivo ao desenvolvimento sustentável através das contratações públicas. A redação original do artigo $3^{\circ}$ apresentava como finalidades da licitação a observância ao princípio constitucional da isonomia e a seleção da proposta mais vantajosa para a administração pública.

É de notar, assim, que essas finalidades, desde sempre consagradas no texto legal, introduziram na mentalidade dos órgãos públicos brasileiros que os certames licitatórios, ao atender esses dois requisitos, estariam contemplando a determinação da lei. Posteriormente, com a edição da Medida Provisória n. 495/2010, houve a introdução, ao lado dessas duas finalidades, a promoção do desenvolvimento nacional.

Entretanto, as discussões em nível mundial sobre a necessidade de preservação do meio ambiente e o papel dos governos nessa questão abriram novos horizontes para adequar a legislação nacional a essa demanda. Não seria mais viável a simples promoção do desenvolvimento nacional a qualquer custo, razão pela qual o texto legal teve de ser adaptado às novas exigências em matéria ambiental.

Imediatamente após a alteração da Lei de Licitações (BRASIL, 1993) que incluiu a promoção do desenvolvimento nacional (sem preocupações de ordem ambiental), ainda no ano de 2010, com a edição da Lei n. 12.349, fruto da conversão da Medida Provisória n. 495/2010, passou-se a definir que, juntamente com as finalidades da observância ao princípio da isonomia e da seleção da proposta mais vantajosa para a administração, a terceira finalidade a ser cumprida pela licitação seria a da promoção do desenvolvimento nacional sustentável.

A inserção dessa expressão no texto da Lei n. 8.666/93 (BRASIL, 1993), como um princípio, criou espaço para que o poder público, em todos os níveis de governo, passasse a se preocupar com a introdução da variável ambiental em suas contratações, ao lado dos princípios da legalidade, da impessoalidade, da moralidade, da igualdade, da publicidade, da eficiência, da probidade administrativa, da economicidade, da vinculação ao instrumento convocatório e do julgamento objetivo.

Não é demais lembrar que princípios são normas que irradiam todo o sistema jurídico. Logo, não é exagero afirmar que o desenvolvimento nacional sustentável deve permear toda e qualquer contratação pública, pelo menos a que for regida pela referida lei. Sendo assim, se uma contratação pública for efetuada com enquadramento nesse diploma, deverá ela atender, qualquer que seja, a critérios de sustentabilidade ambiental. 
O legislador, ao dispor dessa forma, buscou harmonizar normas constitucionais referentes ao desenvolvimento nacional e à preservação do meio ambiente:

Com essas inserções, o legislador procurou destacar a necessidade da harmonização de regras constitucionais: a garantia do desenvolvimento nacional, contida expressamente no art. $3^{\circ}$, II, com a defesa do equilíbrio ambiental, prevista nos artigos 23, VI, 170, VI, 186 e 225. É, sem dúvida alguma, uma nova perspectiva de crescimento nacional que estabelece diretrizes afetas à sustentabilidade como limites ao desenvolvimento nacional conduzido "a qualquer custo" (ALTOUNIAN; CAVALCANTE, 2013, p. 93).

Entretanto, como afirma Moreira (2011), o Brasil ainda não alcançou o nível de desenvolvimento legislativo desejado, uma vez que a norma geral federal de licitações ainda não referencia, de modo suficiente, a variável ambiental nesses processos. Quanto à contratação de obras e serviços, a previsão da Lei de Licitações (BRASIL, 1993) encontra-se em estado de maior evolução, ao prever a elaboração de projeto básico levando em consideração estudos técnicos preliminares que assegurem o adequado tratamento do impacto ambiental do empreendimento.

Essas prescrições encontram-se melhor explicitadas, em consonância com a finalidade de promoção do desenvolvimento sustentável determinada pela Lei n. 12.349/2010. Por outro lado, quanto à aquisição de bens, esse diploma não traz qualquer previsão, deixando o poder público com a determinação genérica do artigo $3^{\circ}$ da Lei de Licitações (BRASIL, 1993).

$\mathrm{Na}$ esfera infralegal, é relevante mencionar a edição do Decreto n. 7.746/2012 (BRASIL, 2012), que regulamenta o artigo $3^{\circ}$ da Lei n. 8.666/93 (BRASIL, 1993), no aspecto pertinente à promoção do desenvolvimento nacional sustentável, para os órgãos da administração pública federal direta e indireta. Esse decreto propõe critérios, práticas e diretrizes gerais voltadas a esse objetivo, permitindo a aquisição de bens e a contratação de serviços e obras através de critérios e práticas de sustentabilidade previamente definidas no instrumento convocatório, justificadas nos autos e resguardando o caráter competitivo do certame, traduzidas em especificações técnicas do objeto ou obrigações da contratada.

O Decreto n. 7.746/2012 especifica, no artigo $4^{\circ}$, as diretrizes de sustentabilidade, cujo teor é a seguir transcrito:

Art. $4^{\circ}$ São diretrizes de sustentabilidade, entre outras:

I - menor impacto sobre recursos naturais como flora, fauna, ar, solo e água;

II - preferência para materiais, tecnologias e matérias-primas de origem local;

III - maior eficiência na utilização de recursos naturais como água e energia;

IV - maior geração de empregos, preferencialmente com mão de obra local;

$\mathrm{V}$ - maior vida útil e menor custo de manutenção do bem e da obra;

VI - uso de inovações que reduzam a pressão sobre recursos naturais; e 
VII - origem ambientalmente regular dos recursos naturais utilizados nos bens, serviços e obras (BRASIL, 2012).

O rol de diretrizes apresentado nesse dispositivo tem caráter exemplificativo, conforme se extrai da leitura do caput do artigo transcrito. Sendo assim, outras diretrizes poderão ser adotadas pelos órgãos da administração pública federal, conforme juízo de conveniência e oportunidade, para conferir o máximo de efetividade ao artigo $3^{\circ}$ da Lei de Licitações (BRASIL, 1993) e ampliar os critérios de sustentabilidade.

O decreto autoriza a administração pública federal a inserir no instrumento convocatório de certame para o fornecimento de bens, cláusula que exija serem estes produzidos a partir de material reciclado, atóxico ou biodegradável, bem como a adoção, pelo contratado, de práticas de sustentabilidade na prestação de serviços. $\mathrm{O}$ cumprimento dessas exigências poderá ser demonstrado pelo licitante por certificação emitida por instituição pública oficial ou instituição credenciada, podendo o edital prever outras formas de comprovação.

Além do Decreto n. 7.746/2012 (BRASIL, 2012), na esfera infralegal, existe a Instrução Normativa n. 1/2010, da Secretaria de Logística e Tecnologia da Informação do Ministério do Planejamento, Orçamento e Gestão (BRASIL, 2010). Esse instrumento tem servido como diretriz orientadora das contratações públicas sustentáveis no âmbito da administração pública federal direta e indireta, uma vez que veicula importante normativo acerca do tema.

Logo de início, a instrução determina que as aquisições de bens e a contratação de obras e serviços devem abranger critérios de sustentabilidade ambiental que abranjam desde os processos de extração ou fabricação, passando pela utilização, incluindo o descarte dos produtos e matérias-primas. Prescreve, ainda, que a adoção de critérios ambientalmente sustentáveis não dispensa a observância ao caráter competitivo dos certames, que deve ser preservado, devendo o instrumento convocatório formular suas exigências de acordo com essa diretriz.

No seu artigo 12, a Lei de Licitações (BRASIL, 1993) determina a observância do impacto ambiental na elaboração dos projetos básico e executivo de serviços de engenharia e obras. Consoante essa determinação, o artigo $4^{\circ}$ da Instrução Normativa n. 1/2010 (BRASIL, 2010) promove o detalhamento das práticas e critérios a serem adotados pela administração pública para a redução do impacto ambiental.

Constata-se ser este um rol de caráter exemplificativo, podendo a administração adotar outras medidas que entender cabíveis para a promoção do desenvolvimento sustentável na contratação de obras e serviços de engenharia. Não poderia ser diferente, pois isto possibilita a 
inserção de novas técnicas e tecnologias que forem surgindo com o decorrer do tempo, o que contribui para manter essa norma atualizada.

Outra importante contribuição dessa Instrução Normativa (BRASIL, 2010) é a preocupação em refrear o consumo desnecessário de bens pela administração pública federal. Para isto, determina que, antes da aquisição de qualquer bem, o órgão deverá verificar se há bens ociosos disponíveis e a possibilidade de sua reutilização.

Tais diplomas normativos, portanto, são voltados à promoção do desenvolvimento nacional sustentável como uma das finalidades da licitação pública, sem, no entanto, olvidar das demais, quais sejam a observância do princípio constitucional da isonomia e a seleção da proposta mais vantajosa para a administração. A busca da harmonização desses três princípios será objeto de análise na próxima seção.

\section{A PROMOÇÃo do DESENVOLVIMENTO SUSTENTÁVEL FRENTE AOS PRINCÍPIOS DA ECONOMICIDADE E DA ISONOMIA}

Os princípios jurídicos têm o condão de funcionar como elementos de harmonização das normas, possibilitando sua coexistência e orientando sua aplicação. Significa dizer que normas aparentemente antagônicas podem sobreviver no interior do ordenamento jurídico, devendo ser devidamente harmonizadas, a depender da situação concreta. Sobre a matéria, Justen Filho afirma que

\footnotetext{
[os princípios] não podem ser examinados isoladamente, aplicando-se a regra hermenêutica da implicabilidade dos princípios. Indica o inter-relacionamento entre princípios, de modo que não se interpreta e aplica um único princípio, isoladamente. Devem considerar-se os princípios conjugadamente e evitar que a aplicação de um produza a ineficácia de outros (citado por COSTA, 2011, p. 32).
}

A dúvida sobre a possibilidade de coexistência harmônica das duas finalidades das licitações públicas preexistentes à que é objeto deste trabalho surgiu desde a sua inserção na lei. A questão que surge é se a inclusão da variável ambiental no objeto das licitações não reduziria sobremaneira a competitividade, fazendo diminuir o número de participantes capazes de concorrer ao objeto e resultando em inobservância do princípio constitucional da isonomia. Outro questionamento que surge diz respeito à possibilidade de haver escassez, no mercado, de bens e serviços sustentáveis, o que faria com que esses se tornassem mais caros, o que poderia ocasionar prejuízos à seleção da proposta mais vantajosa para a administração, afetando o princípio da economicidade. 
De início, compreende-se que a inserção da finalidade da promoção do desenvolvimento nacional sustentável na Lei de Licitações (BRASIL, 1993) não exclui o princípio da isonomia e da busca pela contratação mais vantajosa para a administração pública. Ao contrário, uma vez que o princípio da defesa do meio ambiente possui, igualmente, lugar na Constituição Federal, este deve ser harmonizado aos demais, passando a ser a promoção do desenvolvimento nacional sustentável não uma faculdade para o poder público, mas um dever para o gestor.

Em razão da escassez de recursos públicos e a existência de necessidades ilimitadas a serem satisfeitas, a interpretação corriqueira que se deu, historicamente, ao princípio da seleção da proposta mais vantajosa foi a de buscar o menor preço, a qualquer custo, num viés absolutamente restritivo do princípio da economicidade.

Costa aborda essa questão:

\begin{abstract}
A visão míope, de se considerar a vantajosidade apenas como menor desembolso de recursos financeiros, pode estar relacionada a alguns fatores. A uma, o Brasil, não obstante o crescimento econômico dos últimos anos, sempre sofreu com a limitação de recursos e uma infinidade de necessidades a serem cobertas. Logo, quanto menor fosse o dispêndio de recursos, mais áreas poderiam ser atendidas. Assim, a busca pelo menor preço sempre foi visada pela Administração Pública quando das aquisições de bens e contratações de serviços. A duas, tradicionalmente, as licitações públicas sempre buscavam assegurar a isonomia entre licitantes e a seleção da proposta mais vantajosa para administração, o que na maioria dos casos, era sinônimo de menor preço. Tal prática se consolidou rapidamente, principalmente quando foi instituída a modalidade Pregão pela Lei 10.520/2002 e seu uso se tornou obrigatório para aquisição de bens e serviços comuns conforme Decreto 5.450/2005 (2011, p. 18).
\end{abstract}

Resta, portanto, a pergunta: se o menor dispêndio de recursos públicos não é sinônimo de proposta mais vantajosa para a administração, o que significa, então, dita vantajosidade? Uma resposta elucidativa sobre a questão é oferecida por Torres (2012), para quem a proposta mais vantajosa é aquela que proporciona o alcance do interesse público, que deve ser o elemento norteador de toda a administração, de modo que o cumprimento dos preceitos constitucionais, inclusive o de defesa do meio ambiente por parte do poder público, é elemento que integra esse conceito.

Nas palavras do articulista,

o interesse público é atingido por meio da concretização dos direitos e princípios inseridos na Constituição Federal, como é o caso da garantia ao meio ambiente equilibrado, previsto no art. 225 da Carta Política. Maior vantajosidade não se resume a menor preço dentre todos aqueles produtos e serviços disponíveis no mercado, apesar de este ser um elemento importante para seleção da proposta a ser contratada (TORRES, 2012). 
Portanto, a busca da vantajosidade deve superar a do menor preço, passando a ser enfrentada como a necessidade de concretização do ideal constitucional da garantia do meio ambiente equilibrado através da contratação de bens e serviços com características mais sustentáveis. Dito de outra maneira, a administração pública terá, através da licitação, obtido maior vantagem se alcançar uma contratação sustentável e não necessariamente menos dispendiosa que não observe as diretrizes da sustentabilidade ambiental.

Não significa, com isto, que a administração pública deva abster-se de buscar o menor preço. Antes, deve primar pela otimização dos recursos públicos, em homenagem ao princípio da eficiência, procurando alcançar uma melhor relação de custo e benefício na execução do orçamento público.

Costa (2011) é enfático ao afirmar que a administração pública não pode restringir suas escolhas ao critério do menor preço, mas sim, deve considerar outros aspectos que favoreçam a eficiência dos contratos públicos.

Veja-se:

\begin{abstract}
Ora, limitar-se a escolher o vencedor da licitação exclusivamente pelo fato de seu produto ser o mais barato do ponto de vista financeiro é administrar de forma retrógrada e ineficiente. Atualmente, não se permite mais que as compras governamentais sejam decididas sem que sejam levados em conta aspectos como qualidade, durabilidade, gastos com manutenção, custo de operação, além, é claro, da variável ambiental, entre outros (COSTA, 2011, p. 19).
\end{abstract}

No mesmo sentido, Moreira afirma que

a garantia da sustentabilidade nas licitações acabaria por reduzir os gastos na Administração - e, logo, do contribuinte - tanto porque o consumo limitar-se-ia ao efetivamente necessário quanto em razão das consequências da maior eficiência econômica dos produtos adquiridos e serviços contratados (maior durabilidade, redução de custos de manutenção e de destinação final, opções de reuso ou reciclagem etc.) $(2011$, p. 322).

Pode-se afirmar, por conseguinte, que o critério de menor preço está longe do ideal de seleção da proposta mais vantajosa para a administração. A maior vantajosidade está na satisfação do interesse público, traduzido, no presente caso, no fator ambiental, que, em face do que já foi exposto, constitui interesse público da maior relevância, alçado ao nível constitucional.

Ainda, se o princípio da eficiência impõe ao administrador que escolha os meios apropriados para dar melhor utilização aos recursos públicos, não se pode esperar nada diferente da valorização de diretrizes sustentáveis nas licitações, como uso eficiente e racional desses 
recursos. E se a lei determina que estes sejam bem geridos, de forma proba, a inserção de critérios de sustentabilidade nas licitações encontra-se em perfeita harmonia com a seleção da proposta mais vantajosa.

Finalmente, quanto à harmonização da promoção do desenvolvimento nacional sustentável com o princípio constitucional da isonomia, torna-se interessante consignar o posicionamento exposto por Torres (2012) sobre o tema. Segundo ele,

\begin{abstract}
isonomia não significa que todos devam ser tratados de forma absolutamente igual, mas, sim, que não deve ser admitido tratamento diferenciado em função de circunstância irrelevante para o alcance da finalidade precípua da licitação, que é a de selecionar a proposta mais vantajosa. Também significa que as regras estabelecidas devem ser claras e que não pode haver aplicação dessas regras de forma diferenciada entre os licitantes.
\end{abstract}

Em breve síntese, o autor expressa que há possibilidade de estabelecer tratamento diferenciado entre possíveis fornecedores de bens e prestadores de serviços, desde que este esteja devidamente justificado e seja razoável, no intuito de atender as necessidades da administração.

O parágrafo $1^{\circ}$ do artigo $3^{\circ}$ da Lei n. 8.666/93 (BRASIL, 1993) veda a fixação de cláusulas restritivas à competitividade, que sejam impertinentes ou irrelevantes para o objeto do contrato. Entretanto, é viável à administração pública a delimitação do objeto de tal forma que venha a atender o interesse público, desde que haja o cuidado da não restrição injustificada à competitividade e o favorecimento de determinado licitante.

O mesmo autor explica que, por si só, a organização de um procedimento licitatório implica em fazer restrições (TORRES, 2012). Quando são fixadas determinadas características a um bem ou serviço, naturalmente restam excluídos aqueles modelos que não possuem tais características. Entretanto, todas as escolhas devem ser motivadas, para evitar o favorecimento ou o prejuízo de eventual participante, o que poderia gerar questionamentos em razão do princípio da isonomia.

Assim, quando são considerados critérios ambientais na definição do objeto da licitação, não significa que a administração pública esteja autorizada a fazer quaisquer exigências sob o pretexto de estarem de acordo com a norma constitucional e legal. Não se dispensa o poder público de justificar a opção por critérios ambientais, devendo as restrições ser igualmente motivadas, pois, apesar de o direito ao meio ambiente ecologicamente equilibrado estar consignado no texto constitucional não é um princípio absoluto. Por esse 
motivo, ele deve estar em harmonia com os demais princípios, em particular com o da isonomia e o da eficiência.

Torres (2012) traz um exemplo suficientemente elucidativo:

\begin{abstract}
Assim, por exemplo, quando da definição do projeto básico para a execução de determinado serviço, pode existir uma tecnologia disponível que seja ambientalmente mais correta (digamos, por gerar menos resíduos), mas que ainda seja nova, que poucas empresas a utilizem, com custo consideravelmente superior ao da "tecnologia tradicional”, que implique em prazos maiores para a execução dos serviços. Nessa situação, a Administração deverá avaliar a pertinência de se exigir que o serviço seja prestado com a utilização daquela tecnologia, com benefícios na área ambiental em função dos menores impactos gerados, frente aos aspectos negativos que essa opção acarretaria, como maiores custos, possíveis dúvidas quanto à qualidade e prazo de execução dos serviços, etc. A partir dessa avaliação poder-se-ia decidir, eventualmente, pela não adequação da opção pela tecnologia ambientalmente mais correta.
\end{abstract}

Diante do exposto, verifica-se que nenhum dos três princípios elencados no artigo $3^{\circ}$ da Lei de Licitações (BRASIL, 1993) - isonomia, seleção da proposta mais vantajosa para a administração e promoção do desenvolvimento nacional sustentável - são absolutos. E, justamente pelo fato de permitirem uma flexibilização de acordo com o interesse público, é que podem ser harmonizados. Caberá ao gestor público, no uso de seu poder discricionário, a necessária ponderação desses princípios, para que o preceito constitucional do desenvolvimento sustentável seja viabilizado sem prejuízo dos demais princípios inseridos na Carta da República e na legislação infraconstitucional.

\title{
5 CONCLUSÃO
}

A introdução do princípio do desenvolvimento nacional sustentável entre as finalidades da licitação pública, no artigo $3^{\circ}$ da Lei n. 8.666/93 (BRASIL, 1993), representou um significativo avanço no desempenho do papel atribuído ao poder público na preservação do meio ambiente.

O presente artigo dedicou-se a realizar uma análise conjuntural do ordenamento jurídico brasileiro, de forma ampla, para avaliar o contexto em que a nova norma, veiculada pela Lei n. 12.349/2010, se insere. Logo que veio a lume, o novo princípio suscitou dúvidas quanto à possibilidade de coexistir, harmonicamente, com as finalidades da observância ao princípio constitucional da isonomia e a seleção da proposta mais vantajosa para a administração pública, ambas prescritas pelo mesmo artigo da Lei de Licitações (BRASIL, 1993). 
É possível deduzir que todos os três princípios em comento - promoção do desenvolvimento nacional sustentável, isonomia e seleção da proposta mais vantajosa - têm a possibilidade de se integrar e coexistir na medida do interesse público. Restou, portanto, necessário demonstrar em que medida isto deveria ocorrer.

A alteração da Lei de Licitações (BRASIL, 1993) para nela incluir a obrigatoriedade de o poder público incentivar a promoção do desenvolvimento nacional sustentável e o surgimento de outros instrumentos normativos infralegais para regulamentar esse dispositivo permite verificar que esse conjunto normativo acena para a possibilidade de que esse modelo de desenvolvimento proposto não fere os princípios da isonomia e da seleção da proposta mais vantajosa para a administração nas licitações públicas.

Nesse sentido, é necessário substituir o entendimento, até então consagrado pela prática administrativa, de que a proposta mais vantajosa é a de menor preço. Há que se considerar, como melhor proposta, aquela que garanta maior eficiência no uso dos recursos públicos, passando a ressignificar o conceito do princípio da economicidade. Nessa linha, a seleção da melhor proposta encontra-se intimamente adstrita ao atendimento do interesse público, no presente caso, expresso no artigo 225 da Constituição Federal (BRASIL, 1988), traduzido na obrigação do poder público de zelar pelo direito fundamental ao meio ambiente ecologicamente equilibrado.

Quanto à observância do princípio da isonomia, a escolha da administração por bens e serviços voltados ao desenvolvimento sustentável deve estar pautada em critérios de eficiência e de razoabilidade. Tais critérios devem estar devidamente consignados nas normas do certame licitatório, delimitando adequadamente o objeto a ser contratado. Não podem decorrer de mera vontade do legislador, senão da melhor escolha possível para o atendimento do interesse público. Se o uso de critérios de sustentabilidade não for conveniente ao interesse público, estes não devem ser empregados apenas para atender o princípio constitucional de defesa do meio ambiente, uma vez que não se trata de princípio absoluto.

Conclui-se, portanto, que é possível que o princípio da promoção do desenvolvimento nacional sustentável coexista com o princípio da isonomia e com o princípio da seleção da proposta mais vantajosa para a administração pública, em particular com a face da economicidade e da eficiência. 


\section{REFERÊNCIAS}

ALTOUNIAN, Cláudio Sarian; CAVALCANTE, Rafael Jardim. RDC e contratação integrada na prática. Belo Horizonte: Fórum, 2014.

ARAÚJO, Leane Benevides Ferraz. A caminho da sustentabilidade: o desenvolvimento e a sustentabilidade. In: MANIGLIA, Elisabete (org.). Direito, políticas públicas e sustentabilidade: temas atuais. São Paulo: UNESP, 2011. p. 269-278.

BETIOL, Luciana Stocco; UEHARA, Thiago Hector Kanashiro; LALOË, Florence Karine; APPUGLIESE, Gabriela Alem; ADEODATO, Sérgio; RAMOS, Lígia; MONZONI NETO, Mário Prestes. Compra Sustentável: a força do consumo público e empresarial para uma economia verde e inclusiva. São Paulo: Programa Gestão Pública e Cidadania, 2012. Disponível em: http://a3p.jbrj.gov.br/pdf/CompraSust_web_dupla.pdf. Acesso em: 11 mar. 2019.

BRASIL. Constituição da República Federativa do Brasil, de 5 de outubro de 1988. Disponível em: http://www.planalto.gov.br/ccivil_03/Constituicao/Constituicao.htm. Acesso em: 1 mar. 2019.

BRASIL. Lei n. 8.666, de 21 de junho de 1993. Regulamenta o art. 37, inciso XXI, da Constituição Federal, institui normas para licitações e contratos da Administração Pública e dá outras providências. Disponível em:

http://www.planalto.gov.br/ccivil_03/LEIS/L8666cons.htm. Acesso em: 1 mar. 2019.

BRASIL. Ministério do Planejamento, Orçamento e Gestão. Instrução Normativa n. 1, de 19 de janeiro de 2010. Dispõe sobre os critérios de sustentabilidade ambiental na aquisição de bens, contratação de serviços ou obras pela Administração Pública Federal direta, autárquica e fundacional e dá outras providências. Disponível em:

http://www.comprasnet.gov.br/legislacao/legislacaoDetalhe.asp?ctdCod=295. Acesso em: 1 mar. 2019.

BRASIL. Decreto n. 7.746, de 5 de junho de 2012. Regulamenta o art. $3^{\circ}$ da Lei ${ }^{\circ} 8.666$, de 21 de junho de 1993, para estabelecer critérios e práticas para a promoção do desenvolvimento nacional sustentável nas contratações realizadas pela administração pública federal direta, autárquica e fundacional e pelas empresas estatais dependentes, e institui a Comissão Interministerial de Sustentabilidade na Administração Pública - CISAP. Disponível em: http://www.planalto.gov.br/ccivil_03/_Ato2011-2014/2012/Decreto/D7746.htm. Acesso em: 1 mar. 2019.

CONFERÊNCIA DAS NAÇÕES UNIDAS SOBRE MEIO AMBIENTE E DESENVOLVIMENTO. 1992, Rio de Janeiro. Agenda 21. Capítulo 4. Disponível em: http://www.mma.gov.br/estruturas/agenda21/_arquivos/cap04.pdf. Acesso em: 23 mar. 2019.

COSTA, Carlos Eduardo Lustosa da. As licitações sustentáveis na ótica do controle externo. Trabalho de Conclusão de Curso (Especialização). Instituto Serzedello Corrêa, Brasília, 2011. 
FURTADO, Celso. Pequena introdução ao desenvolvimento: enfoque interdisciplinar. São Paulo: Nacional, 1980.

MACHADO, Paulo Affonso Leme. Direito ambiental brasileiro. 16. ed. São Paulo: Malheiros, 2008.

MOREIRA, Danielle de Andrade. Licitação sustentável: inserção da variável ambiental no sistema de compras e contratações públicas. In: BENJAMI, Antonio Herman; FIGUEIREDO, Guilherme José Purvin de (coord.). Direito ambiental e as funções essenciais à justiça: o papel da advocacia pública na proteção do meio ambiente. São Paulo: Revista dos Tribunais, 2011. p. 299-328.

NEVES, Lafaiete Santos; KLEINMAYER, Luiz Augusto M.; TOCACH, Regis. A transição do desenvolvimento ao desenvolvimento sustentável. Disponível em:

http://www.unifae.br/publicacoes/pdf/IIseminario/pdf_reflexoes/reflexoes_14.pdf. Acesso em: 9 mar. 2014.

PORTO, Uelton Carlos; MELO FILHO, Renato Soares de; DUARTE NETO, José. O desenvolvimento sustentável e as políticas públicas de sustentabilidade: uma análise do documento "our common future". In: MANIGLIA, Elisabete (org.). Direito, políticas públicas e sustentabilidade: temas atuais. São Paulo: UNESP, 2011. p. 29-50.

TORRES, Rafael Lopes. Licitações sustentáveis: sua importância e seu amparo constitucional e legal. Interesse Público - IP, Belo Horizonte, ano 14, n. 71, jan./fev. 2012. Disponível em: http://www.bidforum.com.br/bid/PDI0006.aspx?pdiCntd=77812. Acesso em: 6 dez. 2018.

VEIGA, José Eli da. Desenvolvimento sustentável: o desafio do século XXI. 3. ed. Rio de Janeiro: Garamond, 2008. VIEIRA, Antonieta Pereira; VIEIRA, Henrique Pereira; FURTADO, Madeline Rocha; FURTADO, Monique Rafaella Rocha. Gestão de contratos de terceirização na administração pública: teoria e prática. 5. ed. Belo Horizonte: Fórum, 2013. 